\title{
Regulation of vitamin D and calcium metabolism after gastrectomy
}

\author{
L NILAS, C CHRISTIANSEN, AND J CHRISTIANSEN
}

From the Departments of Clinical Chemistry and Surgery D, Glostrup Hospital, University of Copenhagen, Copenhagen, Denmark

SUMmARY Fifteen men, who had undergone Billroth I gastrectomy and 19 men who had undergone Billroth II gastrectomy were studied with respect to vitamin D and other indices of calcium metabolism. The Billroth I group had hypocalcaemia, raised concentration of serum alkaline phosphatase, and reduced bone mineral content. The same biochemical disturbances were found in the Billroth II group, but bone mineral content was normal. In neither of the groups was found signs of increased bone resorption. The calcium absorption was situated in the lower part of the normal range and the fractional absorption and elimination rates were normal. The $25 \mathrm{OHD}$ concentrations in both groups were reduced $(\mathrm{p}<0 \cdot 05-0 \cdot 01)$ and the $1,25(\mathrm{OH})_{2} \mathrm{D}$ concentrations raised $(\mathrm{p}<0 \cdot 01-0 \cdot 001)$. The $1,25(\mathrm{OH})_{2} \mathrm{D}$ concentrations were inversely related to bone mineral content, but directly related to signs of bone turnover and calcium absorption. We suggest that the high $1,25(\mathrm{OH})_{2} \mathrm{D}$ concentration is the result of a compensatory process with the aim of preventing hypocalcaemia.

While most studies on postgastrectomy bone disease show that the disease is of oesteomalacic nature, ${ }^{1-3}$ there is disagreement with respect to its pathogenesis. Deficient dietary intake of calcium and vitamin $\mathrm{D}^{45}$ and various maldigestive or malabsorptive conditions caused by steatorrhoea ${ }^{5-7}$ are considered causative factors. Study results vary, however, and the literature concerning calcium absorption is particularly conflicting. ${ }^{8-11}$ Findings of low 25OHD concentrations ${ }^{12-15}$ support the opinion that vitamin $\mathrm{D}$ deficiency is a contributory cause.

Whatever the cause, manifest bone disease can develop in two different ways; gradually over several years, finally reaching a symptomatological stage, or as the result of a sudden breakdown in compensatory processes that have hitherto been able to maintain almost normal bone composition. The lack of relationship between the time since operation and manifestation of bone disease ${ }^{13}$ favours the latter view, but no studies have been undertaken with the aim of investigating the regulation of the calcium and vitamin D metabolism after gastric resection.

We present here an investigation in which the

Address for correspondence: L Nilas, MD. Department of Clinical Chemistry. Glostrup Hospital, DK-2600 Glostrup. Denmark.

Received for publication 18 May 1984 altered calcium metabolism after gastrectomy is reassessed from a pathophysiological point of view.

\section{Methods}

PATIENTS AND CONTROLS

We contacted 171 men who had undergone partial gastrectomy three to 14 years before at Glostrup Hospital. Of these 59 had had more than one operation and 61 were excluded for the following reasons: neoplasms (27), liver disease or alcohol addiction (seven), diabetes mellitus (four), immobility (four), lack of cooperation (nine), other diseases (six), and treatment with certain medications (four). Of the 51 who met the inclusion criteria eight had left the district and 35 of the remaining 43 were willing to participate. The study finally comprised 34 (Table 1) who were without conditions known to affect calcium metabolism and who had normal serum asparatate aminotransferase (ASAT) and serum creatinine concentrations. All gave their informed consent. Half of the patients were randomly selected for calcium absorption test. They constituted a true sample of the whole population (Table 1 and 2).

Serum alkaline phosphatase, calcium absorption, and urine values were compared with those in 
Table 1 Comparability of the Billroth I and Billroth II gastrectomy groups. Data for the subpopulation are given in brackets.

\begin{tabular}{lcc}
\hline & $\begin{array}{c}\text { Billroth I } \\
n=15(8)\end{array}$ & $\begin{array}{l}\text { Billroth II } \\
n=19(9)\end{array}$ \\
\hline Age (yr) & $6(0 \cdot 8 \pm 8 \cdot 7$ & $6(0 \cdot 7 \pm 11 \cdot 8$ \\
& $(63 \cdot 4 \pm 8 \cdot 8)$ & $(57 \cdot 7 \pm 9 \cdot 5)$ \\
Interval since operation (yr) & $8 \cdot 8 \pm 2 \cdot 2$ & $10 \cdot 4 \pm 2 \cdot 9$ \\
& $(9 \cdot 6 \pm 2 \cdot 4)$ & $(9 \cdot 8 \pm 3 \cdot 2)$ \\
Height (cm) & $172 \pm 8$ & $174 \pm 5$ \\
& $(172 \pm 6)$ & $(175 \pm 6)$ \\
Present weight (kg) & $69 \cdot 5 \pm 11 \cdot 1$ & $76 \cdot 0 \pm 9 \cdot 2$ \\
& $(70 \cdot 9 \pm 9 \cdot 5)$ & $(77 \cdot 6 \pm 9 \cdot 9)$ \\
Weight at time of operation (kg) & $62 \cdot( \pm \pm 9 \cdot 3 *$ & $71 \cdot 8 \pm 7 \cdot 3$ \\
& $(64 \cdot 6 \pm 8 \cdot 8)$ & $(71 \cdot 3 \pm 7 \cdot 6)$ \\
\hline
\end{tabular}

${ }^{*}=\mathrm{p}<() \cdot() 1$ (Billroth I versus Billroth II gastrectomy groups).

healthy age-matched men (Table 2). Vitamin D metabolite concentrations were compared with values in 20 persons (seven women and 13 men) aged $31 \cdot 5 \pm 5 \cdot 7$ (Fig. 1). As reference groups for bone mineral content values we used 74 healthy men, aged $40-90$ years (mean 56.7 years); and 32 men, aged $26-85$ years (mean $46 \cdot 2$ years) served as reference group for the remaining variables (Table 2).

Vitamin D concentrations were measured by a previously described method. ${ }^{16}$ The method involves extraction with methanol/dichloromethane and separation and purification by means of Sephadex LH-20, Lipidex 5000 chromatography and high pressure chromatography. The 25OHD fraction is measured by ultraviolet detection whereas the dihydroxylated metabolite $1,25(\mathrm{OH})_{2} \mathrm{D}$ was quantitated by a cytosol receptor assay. Interassay variations $(\mathrm{CV} \%)$ are $11 \%$ and $13 \%$, respectively. All blood samples for vitamin D analysis were taken during the same two months (February and March) because of seasonal variations in 25OHD. Parathyroid hormone (PTH) was measured by double antibody technique with determination of the $\mathrm{C}$ terminal fragments. Intraassay variation is $10 \%$. Calcium, magnesium, phosphaie, ASAT, and alkaline phosphatase concentrations were measured by routine techniques (atomic absorption, colorimetry, and enzymatically). Calcium and magnesium concentrations were corrected to a protein concentration of $70 \mathrm{~g} / 1 .{ }^{17}$

Calcium and creatinine were measured in 24 hour and fasting urine by means of SMA- 6 autoanalyser. and hydroxyproline was measured in fasting urine spectrophotometrically by a previous described method. ${ }^{18}$ Interassay variation is $9 \%$.

Bone mineral content was measured by single photon absorptiometry on the distal part of the forearm. The mean of 12 scans, six on each arm was expressed as percentage of a 10 year grouped

Table 2 Biochemical findings in gastrectomised patients compared with controls. Data for the subpopulations are given in brackets. Values are given as mean $\pm I S D$.

\begin{tabular}{|c|c|c|c|}
\hline & $\begin{array}{l}\text { Billroth I } \\
n=15\end{array}$ & $\begin{array}{l}\text { Billroth II } \\
n=19\end{array}$ & Controls \\
\hline Bone mineral content ( $\%$ ) & $\begin{array}{c}89 \cdot 4 \pm 12 \cdot 4^{*} \\
(91 \cdot 7 \pm 12 \cdot 8)\end{array}$ & $\begin{array}{c}100 \cdot 7 \pm 19 \cdot 4 \\
(105 \cdot 7 \pm 16 \cdot 5)\end{array}$ & $100 \pm 16 \cdot 4(n=74)$ \\
\hline \multicolumn{4}{|l|}{ Serum values } \\
\hline Calcium ( $\mathrm{mmol} / \mathrm{l})$ & $\begin{array}{c}2 \cdot 39 \pm 0 \cdot 07 \dagger \\
(2 \cdot 39 \pm 0 \cdot(08)\end{array}$ & $\begin{array}{c}2 \cdot 42 \pm 0 \cdot(07 \\
(2 \cdot 43 \pm 0 \cdot(17)\end{array}$ & $2 \cdot 47 \pm 0 \cdot(09(n=32)$ \\
\hline Phosphate (mmol/l) & $\begin{array}{c}1 \cdot(0 \pm 0 \cdot 1 \\
(1 \cdot 0 \pm 0 \cdot 1)\end{array}$ & $\begin{array}{c}1 \cdot 1 \pm() \cdot 1 \\
(1 \cdot 1 \pm() \cdot 2)\end{array}$ & $1 \cdot 1 \pm 0 \cdot 2(n=32)$ \\
\hline Magnesium (mmol/l) & $\begin{array}{c}0.82 \pm 0.05 \\
(0 \cdot 82 \pm 0 \cdot 05)\end{array}$ & $\begin{array}{c}0 \cdot 83 \pm 0 \cdot(06 \\
(0 \cdot 84 \pm 0 \cdot(05)\end{array}$ & $0.85 \pm 0 \cdot(07(n=32)$ \\
\hline Alkaline phosphatase (U/l) & $\begin{array}{c}206 \pm 61 \div \\
(225 \pm 67)\end{array}$ & $\begin{array}{c}187 \pm 51^{*} \\
(171 \pm 4(0)\end{array}$ & $154 \pm 26(n=15)$ \\
\hline \multicolumn{4}{|l|}{ Urine values } \\
\hline 24-hour $\mathrm{Ca} / \mathrm{Cr}(\mathrm{mmol} / \mathrm{mmol})$ & $\begin{array}{c}0 \cdot 30 \pm 0 \cdot 18 \\
(0 \cdot 29 \pm 0 \cdot 21)\end{array}$ & $\begin{array}{c}0 \cdot 31 \pm 0 \cdot 14 \\
(0 \cdot 32 \pm 0 \cdot 16)\end{array}$ & $0 \cdot 38 \pm 0 \cdot 15(n=17)$ \\
\hline Fasting $\mathrm{Ca} / \mathrm{Cr}(\mathrm{mmol} / \mathrm{mmol})$ & $\begin{array}{c}0 \cdot 18 \pm 0 \cdot 11 \\
(0 \cdot 16 \pm 0 \cdot 11)\end{array}$ & $\begin{array}{c}0 \cdot 20 \pm 0 \cdot 15 \\
(0 \cdot 18 \pm 0 \cdot 13)\end{array}$ & $0 \cdot 20 \pm 0 \cdot 11(n=17)$ \\
\hline Fasting HPR/Cr $(\mathrm{mmol} / \mathrm{mmol})$ & $\begin{array}{c}0 \cdot 011 \pm 0 \cdot 003 \\
(0 \cdot 011 \pm 0 \cdot 003)\end{array}$ & $\begin{array}{c}0 \cdot 012 \pm 0 \cdot 002 \\
(0 \cdot 011 \pm 0 \cdot 002)\end{array}$ & $0 \cdot 011 \pm 0 \cdot 004(n=17)$ \\
\hline \multicolumn{4}{|l|}{ Calcium absorption } \\
\hline Fract $60 \mathrm{~min} \times 20 \% \mathrm{LBM}$ & $(27 \cdot 7 \pm 5 \cdot 4)$ & $(26 \cdot 4 \pm 6 \cdot 4)$ & $32 \cdot 1 \pm 10 \cdot 4(n=11)$ \\
\hline Time delay ( $\min )$ & $(7 \cdot() \pm 2 \cdot 7)^{*}$ & $(7 \cdot 6 \pm 2 \cdot 5)^{*}$ & $11 \cdot 5 \pm 4 \cdot 7(n=11)$ \\
\hline Fract abs rate $\left(h^{\prime}\right)$ & $(1 \cdot 5 \pm 0 \cdot 4)$ & $(2 \cdot 2 \pm 1 \cdot 2)$ & $1 \cdot 8 \pm 0 \cdot 9(n=11)$ \\
\hline Fract climin rate $\left(h^{1}\right)$ & $(0 \cdot 27 \pm 0 \cdot 11)$ & $(0 \cdot 21 \pm 0 \cdot 10)$ & $(0 \cdot 2 \pm 0 \cdot 10(n=11)$ \\
\hline
\end{tabular}

$*=\mathrm{p}<0 .(05 . \quad+=\mathrm{p}<0) \cdot(01$ (patients versus controls). 


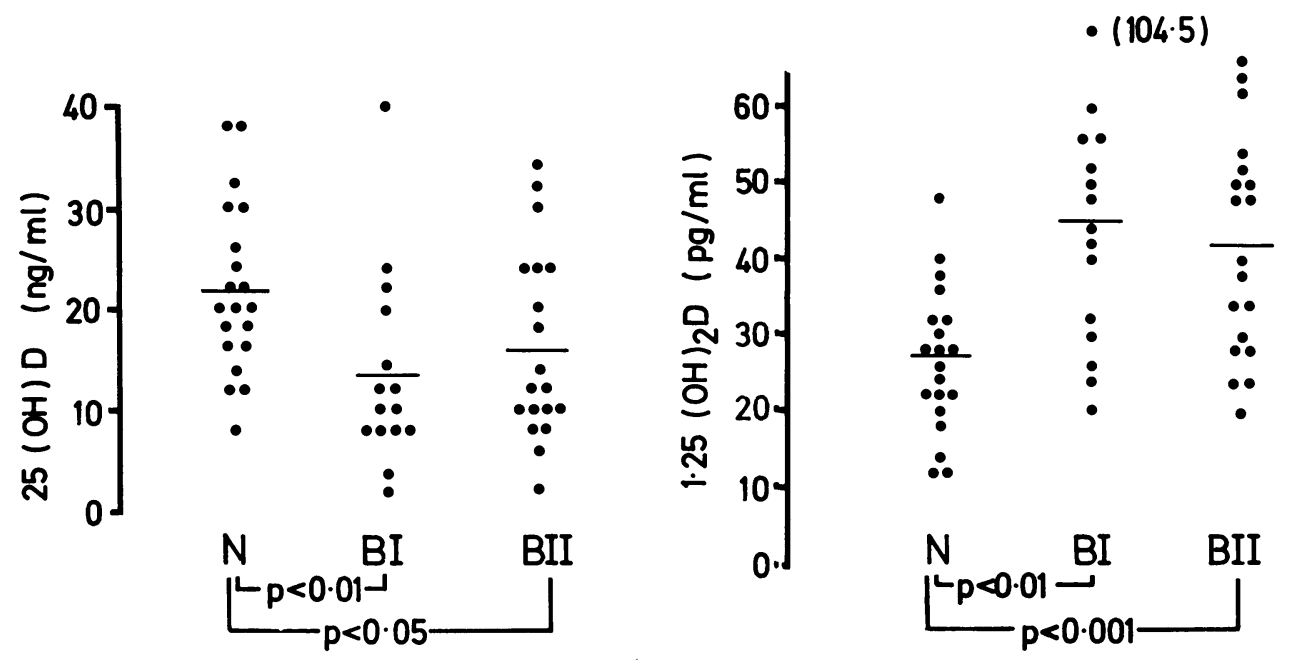

Fig. 1 Serum $25 \mathrm{OHD}$ and $1,25(\mathrm{OH})_{2} D$ concentrations after Billroth gastrectomies compared with normal values.

sex-matched reference population. The bone mineral content measurement has a long term reproducibility of $1.4 \%,{ }^{19}$ and it is highly correlated to total body calcium in both gastrectomised patients and normal subjects. ${ }^{20}$

Calcium absorption was measured by a slight modification of the single isotope technique described by Marshall and Nordin. ${ }^{21} 22$ The oral tracer of $10 \mu \mathrm{Ci}^{47} \mathrm{Ca}$ with a carrier dose of $20 \mathrm{mg}$ calcium ion as $\mathrm{CaCl}_{2}$ in $250 \mathrm{ml}$ water was given to the fasting subjects between 8 and $10 \mathrm{am}$. Blood samples were taken after 10, 20, 40, 60, 90 and 120 minutes and the absorbed fractions were corrected for lean body mass ${ }^{20}$ calculated by the formula of Boddy et $a l .{ }^{23}$ The time delay $\Delta \mathrm{t}$, the absorbed fractions, and the constant fractional absorption and elimination rates were calculated by a non-linear curve fitting programme using a two component model. ${ }^{24}$

\section{CALCULATIONS AND STATISTICS}

The following statistical tests were used: calculation of mean values and standard deviation (SD); Student's $t$ test for unpaired observations, except for calcium absorption for which Wilcoxon's rank sum test was used; and tests of linear correlation.

\section{Results}

Hypocalcaemia, raised serum alkaline phosphatase, and lower than normal bone mineral content were found in the Billroth I gastectomy group. The biochemical findings were similar in the Billroth II group but the mean values for bone mineral content were normal. The mean calcium and hydroxyproline excretions were similar in both groups and did not differ from the normal mean values (Table 2).

The mean calcium absorption curves were almost identical and were situated in the lower part of the normal range (Fig. 2). The only significant differences from normal were a shorter time delay in both gastrectomy groups and a correspondingly increased absorbed fraction after 10 minutes in the Billroth II group (Table 1, and Fig. 2). The calculated fractional absorption and elimination rates were of similar magnitude in both patients and controls (Table 2). In neither group was the absorbed fraction (after 60 minutes and corrected for lean body mass $\left.\left(F_{60}\right)\right)$, related to age or interval since operation.

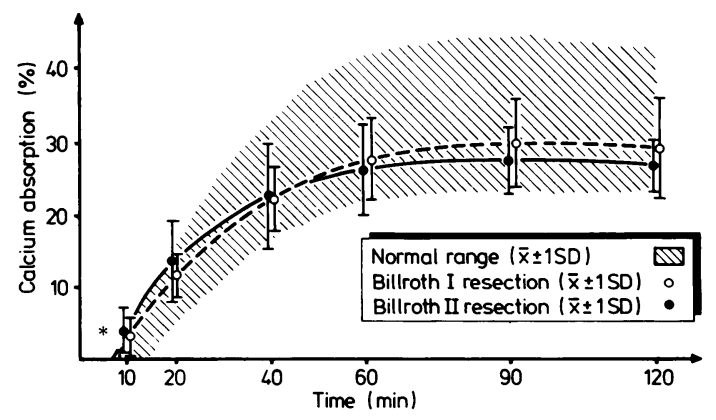

Fig. 2 Intestinal calcium absorption expressed as fraction of oral ${ }^{47}$ Ca dose $\times 20 \%$ of lean body mass. Values are given as mean $\pm I S D$.

${ }^{*}=p<0.05$ (Wilcoxon's rank sum test). 
Figure 1 shows the individual concentrations of vitamin $\mathrm{D}$ metabolites for both the patient groups and the controls. The mean serum $25 \mathrm{OHD}$ was decreased and the mean serum $1,25(\mathrm{OH})_{2} \mathrm{D}$ was increased in both the patient groups compared with the normal subjects. Taking the patients as one group, three had a 25OHD concentration below the normal range $(<4.9 \mathrm{ng} / \mathrm{ml})$ and 16 had a $1,25(\mathrm{OH})_{2} \mathrm{D}$ concentration above the normal range $(>45 \cdot 2 \mathrm{pg} / \mathrm{ml})$. No significant correlations were observed between the two serum vitamin D metabolites, and none were significantly related to age or time since operation. The PTH concentrations were significantly higher in the Billroth I group $(0 \cdot 34 \pm 0 \cdot 11 \mu \mathrm{g} / \mathrm{l})$ than in the Billroth II group $(0.27 \pm 0.04 \mu \mathrm{g} / \mathrm{l}), \mathrm{p}<0.05$. Only two of the patients (both in the Billroth I group) had concentrations above the normal range.

Table 3 gives the linear coefficients of correlation between the relevant variables. The salient features are as follows: bone mineral content was inversely related to the serum $1,25(\mathrm{OH})_{2} \mathrm{D}$ concentration and calcium absorption. Moreover, the serum $1,25(\mathrm{OH})_{2} \mathrm{D}$ concentration was related to the serum alkaline phosphatase (estimate of bone formation), fasting urinary hydroxyproline/creatinine excretion (estimate of bone resorption), and calcium absorption.

\section{Discussion}

The Billroth I and Billroth II gastrectomy groups had an average bone mineral content value of $96 \%$ of the normal value, which is similar to the values of $95 \%^{3}$ and $93 \%$ found in other studies. Because the local bone mineral content value is closely related to the total body mineral content, ${ }^{19}$ there does not seem to be much acceleration of bone loss during the first 10 years after gastric resection in otherwise healthy men. This is also supported by lack of biochemical signs of increased bone resorption. Although the patients in the two resection groups were identical with regard to age, height, and interval since operation, the body weight in the
Billroth I group were nearly $10 \mathrm{~kg}$ less than that in the Billroth II group at the time of operation and this difference largely persisted at the time of the study (Table 1). In spite of the lower bone mineral content values and greater biochemical alterations in the Billroth I group, no conclusion can be drawn about which type of resection carries the greater risk of osteopenia subsequently developing.

In accordance with the almost normal bone mass and the normal calcium excretion rate, we found no evidence of pronounced malabsorption. Estimation of calcium absorption by the single isotope test has shown both higher ${ }^{8-10}$ and lower ${ }^{10-11}$ plasma ${ }^{47} \mathrm{Ca}$ concentrations after gastrectomy. A relation between test values and bone disease has been claimed by some authors ${ }^{10}$ and contradicted by others. ${ }^{11}$ There is a similar disagreement about the role of steatorrhoea, ${ }^{811}$ but increased faecal calcium has often been found in gastrectomised patients. ${ }^{9} 10$ In large population studies of healthy persons and patients with calcium metabolic disorders, including gastrectomised patients, the fraction absorbed after one or two hours, corrected for body weight, is closely related to calcium absorption measured by the balance method ${ }^{21}$ and using a greater carrier dose also with the double isotope test. ${ }^{25}$ In the presence of severe intestinal malabsorption and delayed calcium absorption the curve may continue to rise for two to three hours and calcium absorption will be underestimated if the fraction absorbed is measured after only one or two hours. In this study, however, the maximum values were reached at the same time in the control group and the two patient groups. The two-compartment models may underestimate calcium absorption when calcium turnover is high, but the fractional elimination rates were similar in patients and controls, and the patients had no other signs of accelerated bone turnover. The dependency of the calcium absorption test on simultaneous intake of milk and fat has been evaluated by Arman ${ }^{26}$ and Agnew. ${ }^{8}$ Despite the fact that this method, like other tracer methods, does not necessarily reflect the physiological events, we consider it useful in estimating calcium absorption.

Table 3 Coefficients of correlation between relevant calcium metabolic variables in 34 patients after partial gastrectomy.

\begin{tabular}{|c|c|c|c|c|c|c|}
\hline & $B M C$ & $\mathrm{Ca}$ & Alkaline Ph & FUOHPro/Cr & $25 O H D$ & $1,25(\mathrm{OH})_{2} \mathrm{D}$ \\
\hline Calcium absorption $(n=17)$ & $-0.48^{*}$ & $0 \cdot 24$ & 0.43 & $0 \cdot 37$ & $0 \cdot 16$ & $0 \cdot 54^{*}$ \\
\hline $1,25(\mathrm{OH})_{2} \mathrm{D}$ & $-0 \cdot 38^{*}$ & $0 \cdot 07$ & $0.41^{*}$ & $0 \cdot 42^{*}$ & $0 \cdot 19$ & \\
\hline $25 \mathrm{OHD}$ & 0.02 & $0 \cdot 24$ & $0 \cdot 01$ & $0 \cdot 17$ & & \\
\hline FUOHPro/Cr & 0.09 & $0 \cdot 12$ & $0 \cdot 17$ & & & \\
\hline Alkaline phosphatase & $-0 \cdot 33$ & -0.05 & & & & \\
\hline Calcium & $0 \cdot 16$ & & & & & \\
\hline
\end{tabular}

${ }^{*}=\mathrm{p}<0 \cdot 05$. 
In spite of an inability to relate calcium absorption to a low calcium diet in the elderly, there is no clear evidence of a dependence between age and serum $1,25(\mathrm{OH})_{2} \mathrm{D}$ concentrations. ${ }^{27}$ On the other hand, if such a relation does exist we have underestimated the increase in serum $1,25(\mathrm{OH})_{2} \mathrm{D}$ in our patients as the control group was younger than the patient groups.

Our present study confirms that gastrectomised patients have decreased serum 25OHD concentrations ${ }^{12-15}$ which is not related to bone mineral content $^{2} 28$ or time after operation. ${ }^{1-15}$ The exogenous vitamin D supply is probably the critical factor, but malabsorption and increased turnover might contribute to the low concentrations. The absorption of vitamin D and 250HD has been found normal or just below the normal range after gastrectomies 122931 and a relation to fat excretion has been proposed. ${ }^{12}$ Because 250HD undergoes enterohepatic circulation, ${ }^{32}$ an impaired bile salt excretion or absorption might influence absorption, but none of the patients in this study had symptoms of liver disease and all had normal serum ASAT concentrations.

Our data clearly demonstrate that these patients as a group have raised $1,25(\mathrm{OH})_{2} \mathrm{D}$ concentrations. These raised concentrations cannot be explained by a concomitant increment of the PTH level. The significant relation between $1,25(\mathrm{OH})_{2} \mathrm{D}$ concentrations and calcium absorption, together with the almost normal bone mass, may indicate that the rise of the $1,25(\mathrm{OH})_{2} \mathrm{D}$ concentration is a compensatory process.

\section{References}

1 Blichert-Toft M, Beck A. Christiansen C, Transbøl I. Effects of gastric resection and vagotomy on blood and bone mineral content. World J Surg 1979; 3: 99-102.

2 Tougaard L, Rickers H, Rødbro $\mathrm{P}$ et al. Bone composition and vitamin D after Polya gastrectomy. Acta Med Scand 1977; 202: 47-50.

3 Alhava EM, Aukee S, Karjalainen P. Bone mineral after partial gastrectomy I. Scand J Gastroenterol 1974; 9: 463-6.

4 Pittet PG, Davie M. Lawson DEM. Role of nutrition in the development of osteomalacia in the elderly. Nutr Metab 1979; 23: 109-16.

5 Morgan DB, Pulvertaft $\mathrm{CN}$. Effects of vagotomy on bone metabolism. In: Williams JA. Cox AG, eds. After vagotomy. London: Butterworths, 1969: 161-71.

6 Deller DJ, Edwards RG, Addison M. Calcium metabolism and the bones after partial gastrectomy. Aust Ann Med 1963; 12: 295-309.
7 Eddy RL. Metabolic bone disease after gastrectomy. Am J Med 1971: 50: 442-9.

8 Agnew JE, Holdsworth CD. The effect of fat on calcium absorption from a mixed meal in normal subjects, patients with malabsorptive disease, and patients with a partial gastrectomy. Gut 1971; 12: 973-7.

9 Fujita T, Okuyama Y. Handa N et al. Age-dependent bone loss after gastrectomy. J Am Geriatr Soc 1971: 19: 840-6.

10 Kocian J, Brodan V. New observations on the absorption of ${ }^{47} \mathrm{Ca}$ in patients with partial gastrectomy. Digestion 1975: 12: 193-200.

11 Gregory DH, Uelft RV. Calcium absorption following gastric resection. Am J Gastroenterol 1972; 57: 34-40.

12 Gertner JM, Lilburn M, Domenech M. 25-hydroxycholecalciferol absorption in steatorrhoea and postgastrectomy osteomalacia. Br Med J 1977; 1: 1310-2.

13 Imawari M. Kozawa K. Akanuma Y. Koizumi S. Itakura H. Kosaka K. Serum 25-hydroxyvitamin D and vitamin D-binding protein levels and mineral metabolism after partial and total gastrectomy. Gastroenterol 1980): 79: 255-8.

14 Lilienfeld-Toal HV, Mackes KG, Kodrat G, Ochs H, Sonnenberg A. Plasma 25-hydroxyvitamin D and urinary cyclic AMP in German patients with subtotal gastrectomy (Billroth II). Am J Dig Dis 1977: 22: 633-6.

15 Schoen MS, Lindenbaum J. Roginsky M. Holt PR. Significance of serum level of 25-hydroxycholecalciferol in gastrointestinal disease. Am J Dig Dis 1978; 23: $137-42$.

16 Shepard RM. Horst RL. Hamstra AJ, Deluca HF. Determination of vitamin $\mathrm{D}$ and its metabolites in plasma from normal and anephric man. Biochem $J$ 1979; 182: 55-69.

17 Christiansen C, Næstoft J, Hvidberg EF, Larsen N-E, Petersen B. An easy procedure for in vivo estimation of protein binding and correction of elevated serum values induced by venous stasis. Clin Chim Acta 1975; 62: 65-71.

18 Pødenphant J, Larsen N-E, Christiansen C. An easy and reliable method for determination of fasting urinary hydroxyproline, an estimate of bone resorption. Clin Chim Acta 1984; 142: 145-8.

19 Christiansen C. Rødbro P. Long-term reproducibility of bone mineral content measurements. Scand J Clin Lab Invest 1977: 37: 321-3.

20 Nilas L, Gotfredsen A, Christiansen C. The relationship between local and total bone mineral content after gastric surgery. Scand J Gastroenterol 1984; 19: 591-5.

21 Marshall DH. Nordin BEC. A comparison of radioactive calcium absorption tests with net calcium absorption. Clin Sci 1981; 61: 477-81.

22 Marshall DH, Nordin BEC. Kinetic analysis of plasma radioactivity after oral ingestion of radiocalcium. Nature 1969; 222: 797

23 Boddy K. King PC. Hume R. Weyers E. The relation of total body potassium to height, weight, and age in normal adults. J Clin Pathol 1972; 25: 512-7.

24 Marshall DH. Calcium and phosphate kinetics. In: Nordin BEC, ed. Calcium phosphate and magnesium 
metabolism. Clinical physiology and diagnostic procedures. Edinburgh: Churchill Livingstone, 1976: 268-71.

25 Tothill P. Dellipiani AW. Calvert J. Plasma concentrations of radiocalcium after oral administration, and their relationship to absorption. Clin Sci 1970; 38: 27-39.

26 Arman E, Nilsson LH, Reizenstein P. Studies in the dumping syndrome VI. Calcium deficiency after partial gastrectomy. Am J Dig Dis 1970; 15: 455-62.

27 Lund Bj, Sørensen OH. Lund Bi, Agner E. Serum 1.25-dihydroxyvitamin $\mathrm{D}$ in normal subjects and in patients with postmenopausal osteopenia. Influence of age, renal function and oestrogen therapy. Horm Metab Res 1982; 14: 271-4.

28 Zanzi I, Schoen M, Roginsky MS et al. Skeletal mass and serum levels of 25-hydroxyvitamin $D$ in post- gastectomy patients. In: Norman AW et al, eds. Vitamin D. Biochemical, chemical and clinical aspects related to calcium metabolism. New York: Walter de Gruyter, 1977: 859-61.

29 Thompson GR, Lewis B, Booth CC. Vitamin-D absorption after partial gastrectomy. Lancet 1966; i: 457-8.

30 Stamp TCB. Intestinal absorption of 25-hydroxycholecalciferol. Lancet 1974; ii: 121-3.

31 Lilienfeld-Toal HV. Becker WM. 25-hydroxycholecalciferol resorption test. In: Norman AW et al, eds. Vitamin $D$ and Problems Related to Uremic Bone Disease. New York: Walter de Gruyter, 1975: 355-61.

32 Arnaud SB, Goldsmith RS, Lambert PW, Go VLW. 25-hydroxyvitamin $\mathrm{D}_{3}$ : Evidence of an enterohepatic circulation in man. Proc Soc Exp Biol Med 1975; 149: 57()-2. 